\title{
Eski Yunan ve Roma Dünyasında Şifacı Tanrıçalar ve Şifacı Kadınlar Arasındaki İlişki
}

\section{The Relationship Between Healing Goddesses and Healing Women in the Ancient Greek and Roman World}

\author{
Leyla Aydemir ${ }^{1}$ (])
}

1Sorumlu yazar/Corresponding author: Leyla Aydemir,

İstanbul Üniversitesi, Sosyal Bilimler Enstitüsü, Eskiçağ Tarihi Bilim Dalı, İstanbul, Türkiye

E-mail: leylaaydemir8@gmail.com

Orcid ID: 0000-0002-5453-8426

Başvuru/Submitted: 05.11.2019

Kabul/Accepted: 02.12.2019

Atıf/Citation: Aydemir, L. (2019). Eski Yunan ve Roma dünyasında şifacı tanrıçalar ve şifacı kadınlar arasındaki ilişki. Anadolu AraştırmalarıAnatolian Research, 22, 55-74.

https://doi.org/10.26650/anar.2019.22.643030
ÖZ

Eski Yunan dünyasında MÖ 4. yüzyılın ortasından itibaren kadın şifacıların çalışmalarını onaylayan yazıtlar bulunmaktadır. MÖ 3. yüzyıldan itibaren kadın şifacıların mesleki kimlikleriyle özellikle yazıtlarda anılmaları, onlar hakkında daha detaylı fikir edinmemize yardımcı olmaktadır. Roma'da ise kadın şifacıların mesleki kimliklerine işaret eden epigrafik izlere MÖ 1. yüzyıldan itibaren ulaşılmaktadır. Kadın şifacılara yönelik kayıtların bu kadar az olması, onların Eski Yunan dünyasında MÖ 4. yüzyıldan, Roma'da MÖ 1. yüzyıldan itibaren şifacılık yaptıkları anlamına gelmemektedir. Daha erken dönem için kadın şifacıların varlığını ve çeşitli hastalıkları tedavi ettiklerini onaylayan, şifacı tanrıça metaforları bu bağlamda önem kazanmaktadır. Nitekim insanlar, kendi ihtiyaçları doğrultusunda yarattıkları birçok antropomorfik tanrı ve tanrıça formunda ideal insanı model almışlardır. Bu bağlamda insanların şifacı tanrıçaları yaratırken bilinen kadın şifacıları model aldıkları göz önünde bulundurulduğunda erken dönem Yunan-Roma dünyasındaki şifacı tanrıçalar üzerinden kadın şifacıların, sağaltmanın hangi alanlarında çalıştıklarını belirlemek mümkün olacaktır.

Anahtar Kelimeler: Eski Yunan, Roma, Şifacı Kadınlar, Şifacı Tanrıçalar, Hastalık ve Tedaviler

\section{ABSTRACT}

There are inscriptions in the ancient Greek World that have confirmed the work of female healers since the middle of the 4 th century BC. Starting from the 3rd century BC, women's healers' mention of their professional identities, especially in the inscriptions, helps us to get more detailed ideas about them. In Rome, the epigraphic traces pointing to the professional identities of female healers have been found since the 1st century BC. The lack of the records of women healers does not mean they do healing since the 4th century BC in the ancient Greek-Roman World, but from the 1st century BC. Metaphors of the healer goddess confirms the existence of women healers and the treatment of various diseases in the earlier Greek and Roman worlds, gain importance. Indeed, people have used idealized human forms to create many anthropomorphic gods and goddesses in line with their needs. In this context, it should be taken into consideration that when people create healer goddesses, they model women healers that were known before. From this point of view, it will be possible to determine the areas in which the women healers were working through the healer goddesses of the early period of the Greek-Roman World.

Keywords: Ancient Greece, Rome, Healer Women, Healer Goddesses, Diseases and Treatments 


\section{EXTENDED ABSTRACT}

Introduction and Research Questions: Were there healer women in Ancient Greece and Rome, especially before the Hellenistic Period? Although ancient literary and medical texts are mostly silent; which fields these healer women had knowledge and skills on, and what kind of remedies they were applying? Despite sources do not give concrete examples on healer women in this period, the Greeks and Romans had their own healer goddesses in their pantheons. If gods and goddesses were modeled on ideal humans, then healer goddesses must have reflected the healer women of the Archaic and Classical Periods. Based on these questions and considerations, the abilities and the field of medicine of these healer women in said periods are tried to be determined.

Literature Review: Although hints between the lines of medical and literary works of the Classical Period suggest the existence of healer women, they are silent on their expertise. Inscriptions containing professional terms like "midwife, midwife-physician, physician and chief physician" give invaluable information on the medical abilities of the healer women. However; information on the healer women of the Archaic and Classical Periods is scarce. In the Iliad and the Odyssey, Homer gives information on Greece during both his time and periods preceding him, tells about the wisdom of various goddesses and women on recuperative herbs used for various psychological and physiological sicknesses; presenting the first clues on healer women. While Homer describes Kirke, a sorcerer, with the adjective

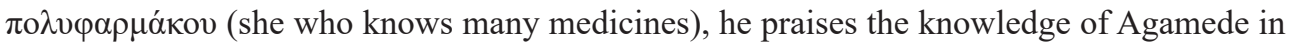
the Iliad, Polydamna and Helen in the Odyssey on medicinal herbs. Unfortunately, except for Homer and a few hints in ancient sources, there are no concrete examples on healer women, not even in the Hippocratic texts. Although Jayne, The Healing Gods Of Ancient Civilizations, Hurd-Mead, A History of Women in Medicine give invaluable information, both fail to make any connection with the women of the period, especially when discussing the healing abilities of the goddesses; they briefly mention some goddesses' healing abilities. The lack of enough study on pre-Hellenistic healer women results in the continuation of the gap. This article does not intend to fill it; but make a small contribution.

Results and Conclusions: The most important indication of women engaged in healing activities in Ancient Greece and Rome since early periods is the existence of healer goddesses. It would not be wrong to think that they were women disguised as goddesses. Attributing divineness to the healing role since earlier times in the lands where Ancient Greek and Roman cultures spread and associate them with healing as a goddess does not change the reality of their healing skills. Until the Hellenistic Period, the non-existence of specific examples of healer women in Ancient Greece and Rome, it is possible to associate it with the belief in these cultures that women do not have some qualities, but also with the boundaries drawn in social life that limit women. However, although women lack virtues men possess by birth, 
a goddess was not thought to be lesser than a mortal man; they were attributed to medicine. Most of these goddesses deal with illnesses of women and children. Why wasn't Artemis, a goddess of the hunt, was a goddess that would heal injuries received in a hunt? Why doesn't Athena, a war goddess, heal the injured of battle? The reason must be the women imitated were healers, who generally dealt with gynecological sicknesses, birth and children illnesses. Yet some women moved beyond these limits in healing; they should have proved their expertise in herbs; forming a model to Athena, Artemis, who cured blindness and Leto, who had surgical skills. It should not be ruled out that there might have been goddesses created based upon healer women such as Kirke and Medeia, who were accused of sorcery when what they did with herbs was considered a miracle in Ancient Greece, or Angitia, one of Rome's first goddesses. It is remarkable to note that some Ancient Greek goddesses that were fundamentally the same in Rome were given broader authority in healing with various epithets: Greek Athena was a special protector of physicians with the epithet of Minerva Medica in Rome, became a goddess remedying people with ear illnesses, curing hair diseases, writing healing prescriptions for various other sicknesses. Diana was associated with reproduction and birth like Artemis of Greece, she became to be known as healer of a broader spectrum of illnesses in Rome; there were many miniature legs, breasts, livers, baby dolls, locks of hair made of wax or stone offered to her. Therefore, healer goddesses, while essentially dealt with birth and healed gynecological and pediatric sicknesses, and their later association with healing illnesses of both genders and their worship accordingly, should be a reflection of healer women that were the basis of healer goddesses' improvement of their medical skills and their application of a broader field of medicine. 


\section{Giriș}

\section{Eski Yunan Dünyasında Kadın Şifacılar Üzerinden Yaratılan Tanrıçalar}

Eski Yunan kaynaklarında kadınlar, zaman zaman farmakolojik bilgiye sahip olarak sunulmaktadır. Kirke, Helen, Medea ve Agamede Yunan mitlerinde ilaç hazırlama becerisine sahip kadınlardan sadece birkaçıdır. Tragedya ve komedilerde de kadınlar sık sık aşk iksirleri ve zehirler hazırlayıp sunmaktadırlar. Bu metinlerde kadınlar genellikle farmakolojik bilgilerini negatif sonuçlar için kullanırken erkekler ise şifalı ilaçlar hazırlarken tasvir edilmektedir (Aristophanes, Thesmophoriazusae, 561-62, 428-431; Euripides, Hippolytus, 479). Kadınların farmakolojik bilgisine yönelik bu karalama politikasına rağmen bitki ve ilaçlar konusunda kontrol edilemeyen bir birikime sahip oldukları açıktır. Nitekim Eski Yunan dünyasında bitki ve büyü bilgisi olan şifacı kadınlardan ilk olarak bahseden Homeros'un

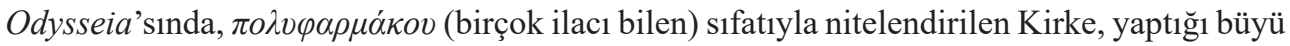
ile Odysseus'un arkadaşlarını domuza dönüştürmüştür (Homeros, Odysseia, X.276-285). Hikayeye göre, Odysseus'u Kirke’nin büyülerine karşı uyaran Hermes, ona olacakları anlattıktan sonra bu büyülerden korunmak için 'molü' denilen gizemli bir bitki verir.

“...kirkenin bütün tuzaklarını büyülerini bir bir anlatayım sana: bir içki hazırlayacak, bir ilaç koyacak içine, ama dinlemez büyü müyü benim sana vereceğim ot,...Argos'u öldüren böyle konuştu ve kopardı otu topraktan, uzattı onu bana ve bir bir saydı özelliğini: çiçeği sütbeyazdl, kökü kapkara, ona molü derlerdi tanrllar arasında... " (Homeros, Odysseia, X.289-291)

Hermes, aslında Odysseus'un arkadaşlarının başından geçenleri anlattıktan sonra aynı şeylerin onun başına da gelebileceği uyarısında bulunup, Kirke'nin şaraba karıştıracağ bitkilerin etkisini yok eden bir bitkiyi Odysseus'a verir. Kirke burada belki de zihni karıştıran bitkiler kullanarak bu savaşçı adamları etkisiz hale getirmiştir. Buna karşılık Hermes, Odysseus'a bir panzehir vererek aklının karışmasını önleyip, onu Kirke'ye karşı korumuştur. Söz konusu olan büyünün esas etken maddesi bitkilerdir ve bu bitkiler özel bir ilgi alanı olarak görüldügünden, Kirke'nin bitkiler hakkındaki derin bilgisi, Homeros tarafından negatif bir biçimde ele alınmıştır. Dolayısıyla $\varphi \alpha \rho \mu \alpha \kappa i \varsigma^{1}$ terimi de burada Kirke üzerinden bir ot/bitki büyücüsü olarak anlamlandırılmıştır. Ölümlüler dünyasında yaşayan, farmakolojik bilgiye sahip, vahşi hayvanları, güçlü ve savaşçı erkekleri uysallaştırmayı başaran, bu başarısını daha çok bitkiler hakkındaki bilgisine borçlu olan Kirke (Homeros, Odysseia, X. 135-137; 210-285), belki de sıradan bir kadındır. Ancak Homeros'un da içinde bulunduğu ataerkil ruha

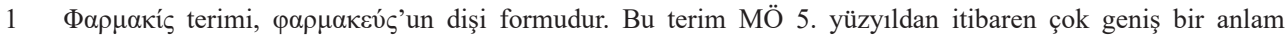
yelpazesiyle antik kaynaklarda yer almıştır. En temel anlamı bitkisel ilaçlarla uğraşan bir kadını ifade ederken

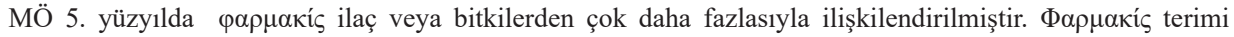
olumsuz çağrışımlarla cadı veya büyücü olarak genellikle tercüme edilmiş olsa da ilaç ya da bitkilerle çalışan aynı zamanda bitki uzmanı anlamına da gelmektedir. Antik kaynaklardaki ifadelerden yola çıkıldığında bu kelimenin kökünün "ilaç bilgisi” anlamından türediği söylenebilir (Irving, 2015, s. 86-87) 
göre, Troia Savaşı'nın kahramanlarını sıradan bir kadının alt etmesi mümkün olmamalıdır belki bunu yapacak kişi bir tanrıça hatta büyücü bir tanrıça olmalıdır.

Homeros'un eserleri hayal ürünü olmasına rağmen MÖ 8. yüzyıl ve öncesinin gerçek dünyası hakkında bilgiler sunmaktadır. Homeros, Ilias'ta Agamede'nin bitki bilgisinden² ve Odysseia'da Mısırlı Polydamna'nın³ verdiği bitkisel bilgiyi kullanan Helen'den bahsederken, onların şifacılık yönlerine dikkat çekmektedir ${ }^{4}$. Homeros'un eserlerinde, Kirke gibi bazı kadınların bitkisel bilgisi negatif ve daha çok büyü ile ilişkili olarak yansıtılırken, Helen ve Agamede gibi başka karakterlerin bitki bilgisi, daha pozitif ve bazen de övgüyle anlatılmaktadır. Hatta MÖ II. binde yaşamış kadın şifacıların selefi olan Helen'e dair bu hikayeden hem Herodotos hem de Diodoros Siculus tarihsel gerçeklik olarak bahsetmişlerdir. (Herodotos, II.116; Diodorus Siculus, I. 97). Ancak şifacı kadınlar hakkındaki sınırlı da olsa pozitif yargıların zaman içinde değiştiği ve bu kadınların cinsiyet hiyerarşisine dayanılarak görmezden gelindiği anlaşılmaktadır.

Rasyonel tıbbın temellerinin atıldığı Klasik Dönem'de bile şifacı kadınların kaynaklarda spesifik bir şekilde varlık göstermemeleri, cinsiyet hiyerarşinin bir sonucu olarak şaşırtıcı değildir. Nitekim tıbbi söylemlerin çok sesli olduğu Klasik ve Hellenistik Yunanistan'da, Hippokrates'in öğretisini savunanlar bu seslerden bir tanesi olup kendilerini baskın otorite olarak var etmeye çalışmışlardır. Bu sırada kolektif bir kimlik yaratma çabası içinde olunmuş ve bu kimliğin sesi ağırlıklı olarak erkek olmuştur. Hippokratik Corpus’taki deontolojik çalışmalardan, Yunan eril niteliklerine dayanan otoriter bir kimlik oluşturma konusundaki eril kaygıyı görmek mümkündür 5 . Burada şifacının (hekimin) temel özellikleri, elit Yunan

2 Homeros, Augeias'ın kızı Agamede'nin yeryüzünün bütün tedavilerini bildiğinden bahsetmektedir (Homeros, Ilias, XI, 735-745).

3 Homeros'un şifacı kadınlar hakkında verdiği ipuçlarında esas ilginç olan durum, Helen'in, Thonis adında Yunanistanlı bir eşi olan ve kendisine dostları iyileştiren, düşmanları ise zehirleyen ünlü bir ilaç 'nepenthe' veren Mısırlı Polydamna ile birlikte tıp eğitimi için Mısır'da bulunmuş olmasıdır (Hurd-Mead, 1938, s. 37).

4 Homeros, Mısırlı Polydamna'nın Helene'ye verdiği “nepenthe " adında bir ilaçtan bahsetmekte ve Misır'daki hekimlerin çok bilgili olduklarını kaydetmektedir (Homeros, Odysseia, IV. 215-235).

5 Örneğin eril kaygının en açık görüldüğ̈̈ metinlerden biri olan Corpus’taki 'Hekim Üzerine' ( $\pi \varepsilon \rho \grave{~ i \eta ~} \tau \rho \rho \tilde{v})$, hekimin taşıması gereken niteliklerin anlatıldığı bir metindir ve bu metnin ilk cümlesindeki özne, eril formdaki iatros (hekim) terimidir. Metinde eril formdaki hekim sağlıklı, temiz, iyi giyinmiş, parfüm kullanmış olmalıdır. $\mathrm{O}$, hayatında sophron yani sağduyu sahibi, akıllı ve kendi kendini kontrol edebilen olmalıdır. Çünkü bu nitelikler kişinin itibarı için önemlidir. Sophrosyne'ye sahip olduğunda hastayı da kontrol altında tutabilir. Hastayı ikna edebilmek için ikna kabiliyetinin güçlü olması ve bir hatip kadar iyi olması gerekir (Hippocrates, The Physician, Chapter I). Bu nitelikler sıralanırken kadın şifacıyı ifade eden herhangi bir terim veya ima metinde söz konusu değildir. Ayrıca Hippokratik Corpus'un genelinde sadece birkaç pasajda meslek alanındaki profesyoneller olarak doğrudan ele alınmamalarına rağmen ỏ $\mu \varphi \alpha \lambda \eta \tau o ́ \mu o \varsigma$ (Littre, VIII, 106), $\alpha \kappa \varepsilon \sigma \tau \rho i ́ \delta \varepsilon \varsigma$

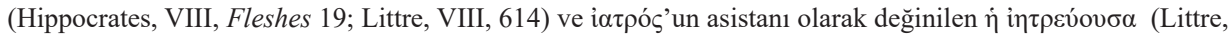
VIII, 144) terimleri, kadın şifacıları ifade etmektedir. Ancak bu kadınların hiçbiri Hippokratik hekimlerin kontrolünde tıbbi uygulamalarda bulunan yardımcı rolünden öteye geçememektedir. Bu durum yine kadının konumlandırıldığı yere yani sahip olmadığı değerler nedeniyle erkeğin kontrolünde olması gerektiği inancına işaret etmektedir. 
erkeğiyle yakından ilişkili olan "retorik 6 yetenek" ve "sophrosyne"7'dir. Saygın bir Yunan erkeği bedeni ve arzuları üzerindeki kontrolünü kaybetmez, beden ve arzularının başka insanlara, özellikle de kadınlara boyun eğmesine izin vermezdi. Erkeğin sophrosyne'si, cesaret ve adalet idealleriyle aynı temele dayanıyor, onları başkalarına karşı üstün kılarak, kendilerine meslek alanında ustalık yapma yetkisi veriyordu (Foucault, 1990, s. 78). Sophrosyne, Yunan erkeklerinin doğuştan getirdikleri bir nitelik sayıldığından, Eski Yunan coğrafyasında kadınla erkek arasındaki farkın temel özelliğidir (Pichanick, 2016, s. 47-63). Buna göre kadın doğuştan öz kontrolünü sağlamaktan yoksundur. Kadın doğası gereği sophrosyne'ye sahip olmadığından ya bir erkek koruyucuya ya da bir otoriteye tabi olmak zorundaydı. Çünkü Eski Yunanlar, kadınların cinsel arzularına köle olduklarına ve fiziksel istekleriyle yönetildiklerine inanıyorlardı. Bu inancın yansımasını Aristophanes'in Lysistrata oyununda görmek mümkündür. Lysistrata, Spartalılarla Atinalılar arasındaki savaşa son vermek için eşlerle birlikte olmayı reddeden bir tür cinsel grev başlattığında, kadınlar arzularını kontrol edemediklerinden bu plana bir süre direniş göstermiş daha sonra kabul etmişlerdir (Aristophanes, Lysistrata, 143-144). Aynı inancın yansıması Thesmophoriazusae' de görülmektedir (Aristophanes, Thesmophoriazusae, 393-394). Burada kadınlar, eşini aldatan, şehvet düşkünü, içki içmeye yatkın ve aşırı konuşan kişiler olarak betimlenmektedir. Bu genel yargı Eski Yunan dünyasında kadını doğası gereği erkeklerden farklı ve ondan daha düşük bir pozisyona hapsetmiştir (Just, 1989, s. 154). Yine de saygın bir Yunan kadını bağlı olduğu erkeğe boyun eğerek erdem ve sophrosyne elde edebilirdi (Foucault, 1990, s. 83). Sonradan edinilen bu niteliklerin derecesi kadının bağlı olduğu erkeğe olan sadakatiyle ölçülüyordu. Kadınlar arzu ve dürtülerine göre hareket ettiklerinde zararla sonuçlanan kontrol yoksunluğu sergilerlerdi. Bu bağlamda erkeklerin en çok tehdit olarak algıladıkları durum, şifacı kadınların bitkiler hakkındaki bilgileriydi. Çünkü bitki bilgisine sahip ve öz kontrolünü yeteri kadar sağlayamayan bir kadın, erkekler için hem korku hem de tehlike yaratıyordu. Kadınlar doğuştan gelen sophrosyne'ye sahip olmadıklarından şifacı olarak güvenilmezlerdi. Bu yüzdendir ki neredeyse Hellenistik Dönem’e kadar halk şifacıları olarak birtakım tedavilerde bulunan kadın şifacılara edebi metinlerde satır aralarındaki küçük ipuçları dışında rastlanamamaktadır. Ancak Hellenistik Dönem'den itibaren şifacılık rollerinin toplumları tarafından kabul edildiği ve kadın şifacılar için artık tıbbi bir literatürün oluştuğu, birçok Eski Yunan ve Roma mezar yazıtından anlaşılmaktadır (IG II² 6873; Firatli ve Robert, 1964, s. 175; IG XII,9, 1129; SEG 33.841; IK Kyme, 37; CIL VI. 4458). Fakat buradaki sorun, Eski Yunan ve Roma coğrafyalarında neredeyse Hellenistik Dönem'e kadar karanlıkta kalan kadın şifacıların rolüdür. Bu bağlamda, kadın şifacıların ihtişamlarının doruğunu yaşadığını söyleyen Achterberg’e göre, MÖ II. bin yılın sonlarına doğru meydana

6 Hippokratik hekim, öncelikle uyguladığı tedavi konusunda hastayı ikna etmek ve rahatlatmak için retorik yeteneğe sahip olmalıdır.

7 Sophrosyne= $\Sigma \omega \varphi \rho \circ \sigma v ́ v \eta$ Sağduyu, akıl sağlı̆̆ı, öz denetim, irade gücü, ölçülülük, 1lımlılık olarak açıklanmıştır (Liddell - Scott, 1996, s. 1751; Çelgin, 2010, s. 646). 
gelen istilalar sonucu sosyo-kültürel düzen değişerek ataerkil bir din ve sosyal düzen Eski Yunanlara hakim olmuştur (Achterberg, 2009, s. 34). Bu ataerkil düzen zamanla kadının rolünü, soyun devamı, evin yönetimi ve erkeğin yardımcılığıyla sınırlama arzusu içine girmiş ve büyük oranda başarılı da olmuştur. Ancak özellikle erdemli kadın olarak nitelendirilen kadının, sosyal hayattan koparılıp evle sınırlandırılması onu bazı zorunluluklardan dolayı sağlık alanından uzaklaştırmaya yetmemiştir.

Kadın şifacıların var olmasındaki en önemli zorunluluklardan biri, Eski Yunan ve Roma dünyasındaki utanç kültürüdür. Utanç kültürü, kontrolün devam etmesi için yaratılmış ve sosyal baskı aracı olarak kullanılmıştır. Bu baskı genellikle ayıp ve toplumdan dışlama şeklinde kendini göstermiştir. Eski Yunan ve Roma toplumlarında utanç kavramı elbette ki günümüzden farklıdır. Diğer birçok toplumda olduğu gibi Yunan ve Roma toplumlarında da suç, günah ve utanç ayrı tanımlanan kavramlar değildir. Konstan, Hristiyanlık inancı gelişene kadar utancın, suçu da içine alan daha geniş bir duygu kavramını temsil ettiğini ileri sürmektedir (Konstan, 2003, s. 1032-1033).

Lloyd, Galenus’un çalışmalarından yola çıkarak kadın hastaların jinekolojik muayenelerinin bazen hekimden başka bir kişi, çoğunlukla da bir kadın yardımcı tarafından yapıldığını yazmaktadır (Lloyd, 1983, s. 70). Utanç kültürü, genel olarak kadınlara yönelik tutumlar açısından çok fazla olumsuzluk ifade etse de, ebe ve şifacı kadınların toplum içindeki fonksiyonlarını ve var olma zorunluluklarını belirlemek açısından önemlidir (Irving, 2015, s. 200). Dolayısıyla dönemin sosyo-kültürel yapısı incelendiğinde, şifanın çeşitli rollerini üstlenmiş ebe, hemşire ve kadın hekim gibi şifacılar için, Eski Yunan ve Roma dünyasında güçlü bir zorunluluğun olduğu açıktır. Buna rağmen antik kaynaklarda olduğu gibi şifa sanatıyla ilgilenen kadınlar yok denecek kadar az mıdır? Yoksa varsayımsal olarak antik kaynaklardaki her bir şifa tanrıçası, Eski Yunan ve Romalı şifacı kadınının temsili bir formu mudur? Eğer böyle ise, Hellenistik Dönem öncesi şifacı tanrıçalar, sağaltmanın hangi alanlarında hizmet vermişlerse kadın şifacılar da o alanlarda hizmet vermiş olmalıdır. $\mathrm{Bu}$ varsayımdan hareketle, aşağıda şifacı tanrıçalar teker teker ele alınarak onlar üzerinden Hellenistik Dönem öncesi şifacı kadınların sağlık alanındaki bilgi, beceri ve hizmetlerine kısmen ayna tutulmaya çalışılacaktır.

Eski Yunan dünyasında MÖ 1. binyıla gelindiğinde tanrıçalar, öfkeli, kinci ve sıklıkla zalim bir doğa atfedilen tanrılardan oldukça güçsüz olarak tanımlanmıştır (Achterberg, 2009, s. 34). İlk tanrıça mitlerinin çoğunluğu da daha güçlü bir tanrının akrabası şeklinde tanımlanarak yeni bir sistemde tekrar var edilmiştir (Capra, 1988, s. 310). Bu bağlamda Hygieia, egemen şifa tanrısı haline gelen Asklepios'un kızı olarak yeniden tanımlanıp Eski Yunanistan'daki tüm tapınaklarda bu formuyla tapınım görmüştür. Hygieia'nın Asklepiosçu kültle olan ilişkisi, sık sık babası ve kız kardeşi Panakeia ile birlikte betimlenmişken, efsanenin yeni versiyonunda iki tanrıça Eski Yunanistan'da olduğu gibi sonraki dönemlerde 
de geçerli olan şifa sanatının "koruma" ve "tedavi” olarak iki yönünü temsil etmiştir (Dubos, 1968, s. 55). Hygieia insanların akıllıca yaşadıkları takdirde sağlıklı olabilecekleri fikrinin kişileştirilmiş hali, Panakeia ise şifalı bitkiler ve yeryüzünden elde edilen çarelerin bilgisi üzerindeki uzmanlaşmadır (Capra, 1988, s. 311).

Eski Yunan dünyasında birer tanrıça olarak saygı gösterilen Asklepios’un karısı ve kızları için tüm Eski Yunanistan'da tapınaklar inşa edilmiş olsa da Epidauros'daki sanatoryum, Eski Yunanistan'daki diğer sanatoryumlar arasında en büyük ve birçok nesil için en önemli olanıdır. Bununla birlikte, Eski Yunanistan genelinde yaklaşık üç yüzden fazla sağlık merkezi ve tapınağın varlığından bahsedilmekte ve buralarda uyku esnasında tanrılar tarafindan verilen tavsiyelerle tedaviler gerçekleştirildiği düşünülmektedir. Tapınakların rahibeleri, daima hastalar için gizemli tedavilerin içinde bulunduğu bir sepet taşırken betimlenmiş ve bu betimlemeler genelde tanrı ya da tanrıçaların siparişleri olarak yorumlanmıştır (Hurd-Mead, 1938, s. 33). Öte yandan Epidauros gibi büyük asklepieionlarda yapılan tedaviler geleneğin biraz daha ötesindedir. Buralardaki rahip ve rahibeler, hünerli kan akıtıcılar, hızlı operatörler ve muhteşem hipnotistlerdir. Muhtemelen buradaki şifacı rahibelerden biri olan, yaklaşık MÖ 4. yüzyılda yaşamış yazar ve şair (Hurd-Mead, 1938, s. 34) Anyte hakkında Pausanias aşağıdaki hikayeyi aktarmaktadır.

“Asklepios kutsal alanının kalıntılarını buldum. Aslında burası Phalysius denilen özel bir kişi tarafindan inşa edilmiştir. O gözlerinden rahatsızd ve neredeyse kör olacağı zaman Epidauros 'taki tanrı elinde mühürlü bir tabletle kadın şair Anyte'yi ona gönderdi. Kadın, tanrınin tezahürünün bir rüya olduğunu düşündü. Fakat kısa süre sonra elinde mühürlü bir tablet gördüğ̈̈ için onun gerçek olduğunu anladı ve bu yüzden Naupaktos'a yelken açtı. Anyte, Phalysius'a mührü açmasını ve yazılan şeyi okumasın söyledi. Phalysius gözleri böyle bir durumdayken yazılanları okumasının mümkün olmadığını düşünüyordu. Fakat Asklepios'tan şifa umduğu için mührü açtı. Balmumuna baktığı zaman görüs yeteneğini geri kazand ve tablette yazllan iki bin altın stateri Anyte 'ye verdi." (Pausanias, Description of Greece, X.38.13, Loeb 297, s. 604-605)

MÖ 7. yüzyıldan önce Asklepios ailesinin şifacı kadın üyeleri seramiklerde, heykellerde ve fresklerde tıptaki uzmanlıklarını tek başlarına uygularken tasvir edilmişlerdir. Ancak daha sonra, babalarının yanında betimlenmenin dışında ender olarak gösterilmişlerdir. Böylece, şifacılık sanatındaki rolleri bir yardımcının pozisyonuna indirgenmiştir. Şifalı ot sepetleri taşırken, Asklepios'u bir hastaya tanıtırken ve onun yönlendirmesiyle sağaltım işlemleri yaparken tasvir edilmişlerdir (Achterberg, 2009, s. 36). Bu durum kadın şifacılara olan saygının azalmasının doğal bir tezahürüdür. Ancak yine de genellikle nazik, sempatik, ölümlülere zarar vermemek için dikkat gösterir bir şekilde tasvir edilen birçok tanrıçanın olduğu bir Yunan şifacı panteonu vardır. Taşıdıkları nitelikler bakımından ideal insan modeli üzerinden yaratılmış bu tanrı ve tanrıçalar, Arkaik Dönem'de bile kadın şifacıların muhtemel gerçekliğini gözler önüne sermeleri açısından son derece önemlidir. Örneğin, Zeus'un kız 
kardeşi olan Demeter, sosyo-politik istikrar, barış ve zenginlikle birlikte sağlık getiren, özellikle de kadınlarla çocukların koruyucusu ve onların hastalıklarına şifa veren, kadınların doğurganlığı üzerinde söz sahibi bir tanrıçadır (Petridou, 2017, s. 103). Bu niteliklerinden dolayı Demeter'i öven MÖ 6. yüzyılın ilk yarısına ait bir şiir, onu Eleusis kralının karısı olan Metaneira'nın oğlunu büyütme, yetiştirme ve hastalıklara karşı onu koruma yeteneğine sahip fakir yaşlı bir kadın kılığında tasvir etmektedir (Dickie, 2005, s. 23). Demeter ve kızı Kore, çocukların diş ağrısını yatıştırmakta, ağrıyan gözleri tedavi etmekte, diğer ağrıları gidermekte aynı derecede beceri sahibidirler. Demeter'in Eleusis'te şifa tanrıçası olarak kabul

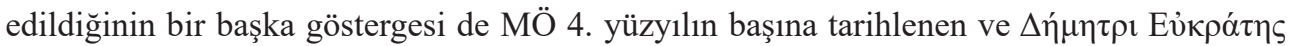
'Eukrates Demeter'e (adadı)' yazısının eşlik ettiği Eukrates'in adak rölyefidir. Rölyefte dikdörtgen plak üzerindeki bir çift göz, kaş ve burun ile bunların tepesinde Demeter ya da kızı Kore'nin olduğu varsayılan, 1şık saçan ${ }^{8}$ bir tanrıça başı göze çarpmaktadır (Petridou, 2017, s. 101-102). Rölyefteki bu betimler Demeter'in gerçekleştirdiği mucizevi bir tedaviden sonra, Eukrates'in görme yeteneğini geri kazandığına işaret ediyor olmalıdır.

Demeter ve Kore'nin göz hastalıklarını iyileştirdiğine yönelik inancın belki de en önemli edebi kaynaklarından biri de Antiphilus'a atfedilen epigramdır:

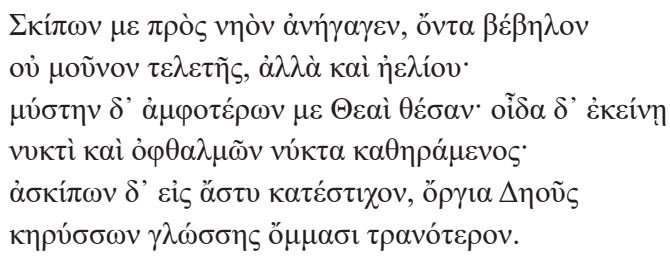

"Bastonum beni tapınağa yönlendirdi, ben habersizken, tanrlçaların her ikisi de benden haberdardı ve o gece gerçekten biliyordum, gözlerimin karanlıktan arındırıldığını. Bastonum olmaksızın dilimden ziyade daha canlı biçimde gözlerimle Demeter'in kutsal ayinini açıklamak için şehre doğru yürüdüm." (Paton, 1918, The Greek Anthology, vol. III, IX. 298).

Tapınakta Demeter ve Kore tarafından gözleri tedavi edilen Antiphilus, belki de tanrıçalara karşı olan şükran borcunu bu mucizevi olayı şehirdeki insanlara göstermek ve bu tanrıçalara olan saygıyı daha çok arttırmakla ödemek istemektedir.

Demeter'in Pergamon'da göz hastalıklarını iyileştirdiği ve bir şifa tanrıçası olarak kabul edildiği, buradaki Asklepion'da yılanların eşlik ettiği Demeter phosphoros " 1 şı getiren" heykelinden anlaşılmaktadır (Meier, 1985, s. 124). Pergamon'daki bu inancı ortaya koyan en somut kaynaklardan biri de Demeter tapınağında bulunmuş yaklaşık olarak MÖ 3. yüzyıla tarihlenen bir dizi terrakotta göz biçimli adaktır. Bu adaklar görme engellilerin göz tedavisiyle

8 Demeter'in 'işık saçan' sıfatıyla, Demeter'e Hymnos 'un 278-280 arasındaki satırlarında anılması, rölyefteki tanrıçayı bütünleyen bir tasvir olarak görünmektedir (Foley, 1994, s. 16-17). 
ilgili bir talepte bulunmak ya da olumlu sonuç alınmış bir tedaviden dolayı şükran sunmak amacını taşıyor olmalıdır (Petridou, 2017, s. 105-111).

Eski Yunan dünyasında doğumla yüz yüze gelen kadınlar da muhtemelen ilk olarak tanrıçalardan yardım istemişlerdir. Belki de bu yüzden, Eski Akdeniz dünyasında geleneksel inanç, Artemis ${ }^{9}$ ve diğerlerinin vasıfları içinde ebelik olan tanrısal yardımcıların varlığını kabul etmektedir. Bu yardımcılar, Eileithyia ve Lokhia gibi genellikle Artemis ile özdeşleşen uzmanlaşmış doğum tanrıçalarıdır (Rouse, 1902, s. 252). Tanrıçaların baş ebesi olan Eileithyia, eğer aksiliği üstündeyse dizlerini kendine doğru çeker, hastasının acısını dikkate almazdı. Bu yüzden Leto'yu, ikizleri olan Artemis ve Apollon'u doğurmadan önce dokuz gün boyunca doğum sancısına katlanmaya mecbur bırakmıştır. Ayrıca kıskançlığından dolayı Herakles’in doğumunu da ertelemiş ve daha sonra da onu epilepsiyle lanetlemiştir (Hurd-Mead, 1938, s. 30).

Daha çocukluk zamanında Artemis'e tapmak çok önemli olduğundan, Artemis genç kadınların kendilerini rahat hissettikleri ve aşina oldukları bir tanrıçadır. O, gençleri gözetmiş, genç kızlar da evlendikleri zaman çocukluk oyuncaklarını ona adamışlardır. Daha sonra da doğurganlık ve başarılı bir doğum için kendisinden medet umulmaya devam edilmiştir. Geleneksel inanca göre Artemis'e çocuksuz bir tanrıça olmasına rağmen doğuma yardımcı olma işi özel bir görev olarak verilmişti ${ }^{10}$. $\mathrm{O}$, başarılı bir doğum bahşedebileceği gibi oklarıyla doğum sırasında kadınlara ölüm de getirebilirdi. Bu yüzden, Eski Yunan geleneğindeki şifa ve hastalık kavramlarında tanrı ve tanrıçalar kilit bir rol oynamıştır. Bundan dolayıdır ki, Homeros ve Hesiodos için bu kavramlar, Apollon ve Artemis'in attı̆ğ okları ifade etmiş, birçok isimsiz cin ve ruh bu hastalıkları getirmiştir. Tanrılar yatıştırıldıklarında tedavi de beraberinde gelmiştir. Daha realist düşünen bazı hekimlerin dini şifaya karşı çıkmalarına rağmen bu anlayış, MÖ 5. yüzyıl Atina’sının aydınlanma çağında bile güçlü bir şekilde devam etmiştir (Demand, 1994, s. 87-88).

MÖ 5. yüzyılın son çeyreğine tarihlenen bir adak stelinde, doğumda kadınlara yardım etmek için gelen iki tanrısal yardımcı gösterilmektedir. Stelde, başarılı bir doğumdan sonraki sahne tasvir edilmektedir. Merkezde bir sandalyede yığılmış vaziyette oturan bir kadın, onun sağında ve arkasında iki kadın figürü vardır. Arkasındaki kadın sol kolunda kundaktaki bir bebeği tutarken, sağ eliyle de oturan kadının başına dokunmaktadır. Tanrısal figürlerin her ikisi de doğal ölçülerden daha büyüktür. Figürlerden biri yukarıya doğru tuttuğu sol eliyle

9 Kadın ve çocukların koruyucusu olan Artemis daha sonraki zamanlarda doğum tanrıçası, Doğu kökenli Eileithya ile karışmıştır (Neuburger, 1910, s. 92).

10 Platon, Artemis'in kısır kadınların ebelik yapmasına izin vermediğini, çünkü insan doğasının tecrübesi olmayan bir konuda başarılı olamayacak kadar zayıf olduğunu, fakat çocuk doğurma yaşı geçmiş olanlara, tanrıçanın kendisine benzediklerinden doğuma yardım etme onurunu verdiğini söyler. Sokrates'in ağzından konuşan Platon şöyle devam eder: "ebeler hamile olanla olmayanı herhangi bir kişiye göre daha iyi bilmeliler; dahası ebeler ilaç ve büyüler sayesinde doğum sancısını azaltabilir ya da arttırabilirler. Eğer isterlerse doğumda zorlananların dayanmasını sağlayabilir ya da düşük yaptırabilirler. Göbek bağı kesme yetenekleriyle gurur duyarlar." (Platon, Theatetus, 149b-150b) 
meşale taşımakta ve her iki figür de yukarıdan kadına bakmaktadır. Richter, bu tanrısal çiftin Hygieia ve Asklepios olduğunu iddia etmektedir (Richter, 1954, s. 44, no. 67). Demand ise ellerinde meşale taşıdıkları için bunların Eileithyia ve Artemis Lokhia olduğunu savunan görüşü daha muhtemel görse de, aslında bu tanrısal çiftin, mutlu sonlardan sorumlu tanrıçalar olabileceğinin de altını çizmektedir (Demand, 1994, s. 88). Bunlara ek olarak, başka arkeolojik buluntular da çeşitli tapınaklarda yapılan adak formlarında bu tanrıçaların yardımına başvurulduğuna dair çok sayıda kanıt sunmaktadır (Rouse, 1902, s. 251-258). Söz konusu çoğu ithaf yazıtı basit formdadır ve tanrıçalar tarafından bağışlanmış olan lütuf açıkça belirtilmemiştir. Bazılarında ise başarılı bir doğum ve erkek çocuk için tanrıçalara açıkça şükranlar sunulmuştur. Delos'taki Kynthos Dağı'nda yer alan Artemis Eileithyia kutsal alanında bulunan iki adağın yer aldığı bazı sunular açık ve net olup, burada hamile olarak yalvaran bir kadın tasvir edilmiştir (Demangel, 1922, s. 78-85). Yine doğum anının taş ya da kil üzerine tasvir edildiği sahneler Kıbrıs’ta da bulunmuştur (Dikaios, 1961, s. 204).

Diğer bir şifacı tanrıça Eski Yunan dünyasında kendisi için birçok sunak yapılmış ve genellikle kadınlar tarafından kendisinden çocuk istenen yani kısırlık sorunlarına çözüm getirmesi için tapınılan Genetyllis’tir. Genetyllis, uzun bir khiton giymiş ve yüzyıllardır ebelerin sembolü olan bir meşale taşırken resmedilmektedir. Tanrıların büyük annesi Rhea da şifa veren Apollon ile birlikte tapınım gören şifacı bir tanrıçadır. Rhea'nın diğer tıbbi partneri ise çocuk doğurmaya yardım eden Artemis’tir. Ayrıca çocuk hastalıklarının uzmanı olan Hekate, çocukların diş çıkarma sürecinde ateşlendikleri vakit onlara itboğan otu çayı içirerek bu süreç boyunca onları rahatlatmaya çalışmıştır. Bundan dolayı, Zeus'un kendisi bile onu hemşire anne olarak adlandırmıştır (Hurd-Mead, 1938, s. 30-32). Yine Helios'un Rodos'taki iki kızı şifacılar ve ebeler gibi tapınım görmüştür. Oropos'ta11 Asklepios'un kızlarının dışında Athena, Artemis, Aphrodite ve Leto şifacı tanrıçalar olarak tapınım görmüştür. Bir güvercin formunda görünen Aphrodite, çocukların ateşlenmesinde ve cilt hastalıklarında uzmandır. Artemis ve Athena'nın bitkileri kullanarak körlüğü iyileştirmelerine inanıldığ gibi cerrah olan Leto'nun, Aeneas'ın yaralarını iyileştirdiği ve zor doğumlarda görev aldığı bilinmektedir. $\mathrm{Bu}$ yüzdendir ki kendisine karşı minnettarlığın bir göstergesi olarak fildişi, altın, gümüşten kol ve bacaklar sunulmuştur (Ward, 1988, s. 2).

Şifa panteonunun en önemli şifa tanrıçaları arasında, nitelikleri bakımından körlüğü gideren Athena, zehirleri ve onların panzehirlerini bilen Medeia, Kirke, cerrah Leto ve daha başka tanrıçalar sayılabilir. Pallas Athena, tıp alanındaki şifacıların sembolü olan şakayık bitkisini, kendisinin etkili tedavisi olarak kullanmıştır. Medeia ve Kirke panzehirlerde uzmanlaşırken, Kheiron'un kızı Okyroe hastalarını tedavi etmek için yine şakayık bitkisini kullanmış, Argos'ta da Hera, şifacı tanrıçaların başı olarak kabul edilmiştir (Hurd-Mead, 1988, s. 29-32). En önemli şifacı tanrıçalardan olan Hygieia ise daha özel bir yere sahiptir

11 Attika bölgesinin doğusunda bulunan küçük bir yerleşim yeri. 
ve genelde tıbbi bilgeliğin sonsuzluğunun sembolü olan yılan atribüsüyle tasvir edilmiştir. Hygieia zaman zaman her şeyi iyileştiren Girit tanrıçası, Athena'nın tezahürlerinden biri olarak da yorumlanmıştır (Capra, 1988, s. 310; Graves, 2010, s. 224).

\section{Roma Dünyasında Kadın Şifacılar Üzerinden Yaratılan Tanrıçalar}

Roma’nın erken dönem kadın şifacılarını, tanrıçalar üzerinden anlamaya çalıştığımızda yine zengin bir şifacı tanrıça panteonu ortaya çıkmaktadır. Roma'da rasyonel tıbbın henüz varlık göstermediği erken zamanlarda, Romalılar tıpkı Eski Yunanlar gibi sağlık sorunları yaşadıkları durumlarda, sağlıkları üzerinde güç sahibi olduğuna inandıkları bazı tanrı, tanrıça ve ruhlardan yardım istemişlerdir. Romalılar genellikle yardım istedikleri ruhları, Scabies (baş kepeği, kabuk; uyuz, kaşıntı), Fecunditas (verimlilik, bereketlilik), Angerona (kalpteki ağrı, üzüntü ya da farenjit) gibi şifalandırdıkları hastalıklarla özdeşleştirmişlerdir (Monaghan, 2014, s. 267). Nero'nun bir tapınak adadığı Fecunditas, verimliliği ve doğurganlığı sembolize ederken genellikle kucağında çocuk tutan bir kadın olarak tasvir edilmiştir (Tacitus, Annales, XV.23). Doğurganlığı temsil eden Fecunditas'ın dışında Carmentis (Carmenta), Comitia, Diana, Egeria, Genita Mana, Iuno (Iuno Luciana), Iuturna, Mater Matuta ve Natio (Nascio) gibi özellikle doğum anı ve doğurganlıkla ilgilenen şifacı tanrıçalara Romalı kadınlar özel bir sayg1 göstermişlerdir (Jayne, 1925, s. 415-455).

Roma'nın şifacı tanrıça panteonundaki diğer tanrıçalara gelince, Eski Yunan dünyasından çok farklı olmadıkları görülmekte, hatta buradaki çoğu şifa tanrıçasının Romalılaştırılmış Eski Yunan tanrıçası olduğu anlaşılmaktadır. Bu yüzden farklar olsa da panteondaki şifacı tanrıçaların görevleri zaman zaman genel hastalıkları kapsamasına rağmen daha çok kadın ve çocuklarla sınırlandırılmıştır. Livius, MÖ 293'teki yıkıcı veba salgını sırasında son çare olarak Epidauros'tan çağırdıkları Asklepios'tan önce Romalılar büyük bir sağlık tanrı veya tanrıçasına sahip değillerdi bilgisine yer vermektedir (Livius, X. 47. 6-7; XXIX.11). Achterberg, Romalıların uzun yıllar boyunca iyiliklerine karşılık kutsal alanlar ve görkem vaat ederek başka ülkelerin tanrılarından yardım dileyip onları ayarttıklarını ileri sürmektedir (Achterberg, 2009, s. 41). Bu bağlamda Eski Yunan dünyasında Athena'ya karşılık gelen Minerva genel şifacı ve koruyucu, Mater Matuta ise doğurganlık ve emziren annelerin koruyucusu olan bir şifacı tanrıçadır. Etrüsk-İtalik panteonundaki en esrarengiz tanrıçalardan Mater Matuta'ya doğum sırasında anne ve bebeği koruyan, bebeklerin doğması için rahmi açan tanrıça olarak saygı gösterilmiştir (Carroll, 2019, s. 4; Hurd-Mead, 1938, s. 48; Achterberg, 2009, s. 41; Lomas, 2018, s. 64). Nitekim Satricum'daki Mater Matuta tapınağında, kadın doğurganlığı ve anneliğe doğrudan işaret eden adak rahimler ${ }^{12}$, çocuklu

12 Rahim biçimindeki adaklar hakkında ayrıntılı bir makale kaleme almış Flemming, Eski Akdeniz dünyasındaki tapınak ve kutsal alanlarda yaygın olarak bulunan rahim şeklindeki adakların; doğurganlık, üreme, uteros hastalıkları ve kadın sağlığıyla ilişkili olduğu yorumunda bulunurken, bu adaklar hakkında tartışmalar olduğunun ve bazı akademisyenlere göre bu adakların tümü ya da bir kısmının hamilelik ve doğum gibi daha spesifik anlamlar taşıdığının altını çizmektedir (Flemming, 2017, s. 112-133). 
kadın figürleri ve kundaklanmış bebekler bulunmuştur (Smith, 2000, s. 143; Carroll, 2019, s. 2-8). Bu nesnelerin, çocukların sağlığını ve hayatta kalmasını güvence altına alan tanrıçanın şifalandırma lütfuna karşılık adaklar olabileceği dikkate alınmalıdır.

Savaşçılıkta olduğu kadar tıp becerisinde de yetkin olan Minerva, Minerva Medica epithetiyle hekimlerin özel hamisi, kulak hastalıklarına şifa veren, saçları onaran ve başka hastalıklar için şifa reçeteleri yazan bir tanrıçadır (Jayne, 1925, s. 434). Esasında Eski Yunan şifa panteonundaki Artemis, Demeter ve diğer tanrıçalar gibi, Athena'nın şifacılık becerilerinin Roma'ya ithal edildiği anlaşılmaktadır. Daha geniş bir alanda tıbbi bilgiye sahip olarak tasvir edilmiş Roma’nın Minerva’sı olan Eski Yunan Athena’sı, körlüğü gideren ve şakayık bitkisini, kendisinin etkili tedavisi olarak kullanan tanrıça olarak tapınım görmüştür (Hurd-Mead, 1988, s. 29-32). Minerva gibi doğum ve doğurganlık alanının dışında tedaviler gerçekleştiren, Yunan kökenli olduğu varsayılan İtalya'nın ilk tanrıçalarından Angitia, bitkilerin tıbbi yararları üzerine uzmanlaşmıştır. Angitia Roma şifa panteonunda favori bir tanrıça olmasa da bitkisel zehirlerin ve panzehirlerinin kaşifi ayrıca zehirli hayvanlar tarafından ısırılan insanları büyü ile iyileştiren bir tanrıçadır (Vergilius, Aeneas, VII. 758-759). Roma'nın en eski şifacı tanrıçalarından biri de sağlığın, bolluğun sağlayıcısı, yetişkinlerin yaşamını ve refahını gözlemleyen Anna Perenna'dır (Jayne, 1925, s. 417-418).

Yine Roma'da özellikle kadınların tapındığı Bona Dea doğurganlığın, uzun ömrün ve sağlığın sembolüdür (Adkins, 2004, s. 284). Hurd-Mead, Bona Dea'nın Aventine Tepesi'ndeki tapınağında, kısırlığın tedavisinde kullanılan bitkiler ve kutsal yılanlarla dolu bir mağara bulunduğunu ve Eleusis’teki Demeter tapınağındaki gibi bu tapınakta da tanrıçaya domuz ve para sunulduğunu, tanrıçanın kutsal alanında kadın hastalıklarının tedavisi için sadece kadın hekimlere izin verildiğini yazmaktadır (Hurd-Mead, 1938, s. 48-49). Richardson, şifacılığın sembolü olan yılanların zarar görmeden serbestçe dolaştıklarını, tanrıçanın kutsal alanındaki erkek ve kadın görevlilerin gerektiğinde çok çeşitli ilaçlar yaparak insanları tedavi edebildiklerini fakat erkeklerin tapınağa girmesine izin verilmediğini ifade etmektedir (Richardson, 1992, s. 60). Ancak belirtilen bu durum erkeklerin tanrıçadan şifa ummadıkları ya da tanrıçanın hizmetkarları tarafından tedavi edilmedikleri anlamına gelmemektedir. Erkeklerin, Bona Dea'nın tapınağına girmeleri ve törenlerine katılmaları yasak olsa da sağlık sorunları yaşadıklarında tanrıça ve rahibeleri tarafından sağlanan tıbbi yardıma başvurabildikleri aşağıdaki yazıttan anlaşılmaktadır.

Felix publicus / Asinianus pontific(um) / Bonae Deae Agresti Felicu(lae?) / votum solvit iunicem alba(m) / libens animo ob luminibus / restitutis derelictus a medicis post / menses decem bineficio Dominaes medicinis sanatus per / eam restituta omnia ministerio Canniae Fortunatae. (CIL VI. 68; ILS 3513; Brouwer, 1989, s. 53, no. 44). 
"Rahiplerin hizmetinde köle olan Felix Asinianus, Bona Dea Agrestis Felicula'ya karşı yeminini istekli ve gönül rahatlı̆̆ içinde yerine getirdi, görme yeteneğini geri getiren tanrıçaya şükrederek beyaz bir düveyi kurban etti. Hekimler pes etmesine rağmen $O$, sahibenin yardımıyla ilaçlar alarak on ay sonra (görme yeteneğini) geri kazandl. Hizmetkar olarak onun sayesinde Cannia Fortunata'nın görev süresi boyunca her şey onarldı." (çeviri: Brouwer, 1989, s. 53).

MÖ 1. ile MS 1. yüzyıllar arasına tarihlendirilen bu yazıtta da görüldüğü üzere Bona Dea, kadın ve çocuk hastalıkları için daha çok tapınılan bir tanrıça olmasına rağmen erkeklerin de mustarip olabileceği hastalıklara şifa veren bir tanrıçadır (Brouwer, 1989, s. 53). Nitekim Eski Yunan şifa tanrıçası Panakeia ile özdeşleştirilen Bona Dea'nın genel şifacılık rolünün ön plana çıkarıldığı epithetlerinden 'Oculata Lucifera' gözleri şifalandıran, 'Bona Dea Aurita' kulakları şifalandıran anlamlarına gelmektedirler (Brouwer, 1989, s. 346, 198; Jayne, 1925, s. 422). Yazıttaki diğer bir önemli nokta ise tedavinin muhtemelen Bona Dea'nın rahibesi olan bir kadın tarafından yapılmış olmasıdır. Hekimler Felix Asinianus'un görme yeteneğini kazandıramayıp pes ettiklerinde, nasıl bir tedavi uyguladığı yazıttan anlaşılamamasına rağmen, bu kadının uyguladığı tedavi sonuç vermiş ve Felix Asinianus görme yeteneğini geri kazanmıştır.

Şifacılıkla ilişkilendirilen ve bu özelliklerinden dolayı birçok tapınak inşa edilen diğer iki tanrıça Feronia ve Fortuna'dır. Fortuna döllenmeye izin veren tanrıça olduğundan, bebek sahibi olmayı arzulayan bütün genç kadınların ve verimli mahsul almak isteyen çiftçilerin tanrıçasıdır (Hurd-Mead, 1938, s. 49; Monaghan, 2014, s. 271). Kuzey Roma'daki tapınağ1 MÖ 6. yüzyıla kadar dayandırılan ve muhtemelen Sabin kökenli olan Feronia, Roma'nın son zamanlarına kadar tapınım görmüş bir tanrıçadır (Jayne, 1925, s. 425; Monaghan, 2014, s. 279-280). Diğer özelliklerinin yanı sıra doğurganlık bahşeden ve doğuma yardım eden bir tanrıça olarak saygı görmüştür (Daly, 2009, s. 51). Ateşli hastalıkları önleme ya da tedavi etme becerisine sahip Febris, genel olarak ateşlenmeleri ifade eden Dea Febris adıyla anılırken, zamanla sıtmanın ayrıntılarını ifade eden Dea Tertiana ve Dea Quartana epithetleriyle öne çıkmıştır (Jayne, 1925, s. 462; Daly, 2009, s. 56-57). Cloacina, tıpkı Febris gibi ateşli hastalıkları tedavi eden bir diğer şifacı tanrıçadır. Temelde Roma kanalizasyon sistemini denetimi altında tutan ve böylece hastalıkların yayılmasını önleyen tanrıça, doğal olarak ateşli hastalıkları da kontrol altında tutmuş ve bu niteliğinden dolayı Romalılar ona bir şifacı tanrıça olarak tapmışlardır (Jayne, 1925, s. 460; Hurd-Mead, 1938, s. 49). Carna hem erkeklerin hem de kadınların kalp, karaciğer, akciğer ve diğer iç organlarını koruyan tanrıçadır. Romalılar sindirim organlarını koruyan ve şifa veren tanrıçaya, vücudun beslenmesi için en iyi gıda olduğuna inandıkları domuz yağı ve fasulye yemeğini dualar eşliğinde sunarak, ona olan minnettarlıklarını dile getirmişlerdir (Jayne, 1925, s. 458; HurdMead, 1938, s. 49; Monaghan, 2014, s. 269). 
Yaşam ve ölüm üzerinde söz sahibi, hastalıkları yaratan ve tedavi eden bir tanrıça olduğuna inanılan Magna Mater ${ }^{13}$, kısır kadınların çocuk sahibi olmak için başvurdukları özel bir tanrıçadır. Romalılara göre büyü gücüne de sahip olan tanrıça, çeşitli büyü ve tılsımlarla tüm hastalıkları tedavi edebilmiştir (Jayne, 1925, s. 486). Tanrıçanın tüm hastalıkları tedavi ettiğine yönelik Roma inancından hareketle Gallia Narbonensis'deki Arausio'da bulunmuş insan ayağı şeklindeki mermer adağın ${ }^{14}$ tanrıçanın şifa niteliğiyle ilgili olma olasılığı güç kazanmaktadır ${ }^{15}$. Benzerlerinin daha sonra tekrar ortaya çıktığ 1 (Çapar, 1978, s. 175-176) bu adağı tanrıçaya sunan kişinin, ayağıyla ilgili bir hastalığa yakalandığı ve hastalığın iyileşmesi için yardım dilemek ya da iyileştirilmiş bir ayak için şükranlarını sunmak amacıyla adağı, tanrıçaya sunmuş olduğunu düşünmek sıra dışı değildir ${ }^{16}$. Ayrıca şifacı tanrıçalara istekte bulunmak ya da şükran sunmak amacıyla adakta bulunulduğuna yönelik başka örnekler de mevcuttur. Örneğin Delos'taki Kynthos Dağı'nda yer alan Artemis Eileithyia kutsal alanında elde edilen iki adağın yer aldığı bazı sunular açık ve net olup, burada hamile olarak yalvaran bir kadın tasvir edilmiştir (Demangel, 1922, s. 78-85). Yine doğum anının taş ya da kil üzerine tasvir edildiği sunular Kıbrıs’ta bulunmuştur (Dikaios, 1961, s. 204).

Roma'da üstün derecedeki şifacı tanrıçalardan bir diğeri de Diana'dır. Kadınların bütün hastalıklarını iyileştirmesi, özellikle de doğum anına hükmetmesi, Diana’nın şifacılık niteliklerinin en önemlilerindendir. Diana yani Artemis, kadın hastalıklarında olduğu kadar çocuk hastalıklarında da uzman bir tanrıçadır (Jayne, 1925, s. 446). Bununla birlikte, Diana'ya hastaların minnettarlıklarının bir göstergesi olarak birçok minyatür bacak, göğüs, karaciğer, oyuncak bebek, gerçek ya da sahte saç tutam $1^{17}$ gibi hastalıklı organlarının kil, balmumu veya taştan birer minyatürünü sunduklarını ve bu sunulardan onun genel bir şifacı olarak kabul edildiğini görmekteyiz (Hurd-Mead, 1938, s. 29-32).

13 Tanrıların anası olduğuna inanılan Magna Mater'in Roma’ya Anadolu'dan ithal edilmesi II. Pön savaşı sırasındadır. Bu savaşta bir taraftan Hannibal'in istilası diğer taraftan sık görülen taş yağmurları (dolu) Romalılarda tanrıları kızdırdıklarına yönelik bir inanç geliştirmiş ve Romalılar bunun için çareler aramaya başlamıştır. Sybil kitaplarına başvurduklarında biliciler Phrygia'dan Magna Mater'i getirmelerini önermiş, böylece kutsal siyah bir taş (muhtemelen meteor) MÖ 204'te Roma'ya getirilmiştir. Getirildikten sonra uzun yıllar tapınım gören tanrıçanın tüm varlığı içine alan koruyuculuk niteliğinin kapsamında insanları hastalıklardan iyileştirme fonksiyonu oldukça önemli ve kültünün daimi bir özelliğidir (Livius 34. 3; 38.18; 29.10-14; Strabon 12.5.3; Achterberg, 2009, s. 41; Jayne, 1925, s. 486).

14 CIL XII. 1223; Ayak şeklindeki mermerin üzerine [Mat]ri deu[m] 'Tanrıların Anası' yazısı oyulmuştur.

15 Petridou'ya göre tapınak ve kutsal alanlardaki anatomik adaklar ya bir tedavi talebi ya da şükran sunusu olarak işlev görmüş olabilir (Petridou, 2017, s. 98).

16 Arkelojik araştırmalarda insan ayakları, elleri, gözleri vb. şeklindeki terrakotta adakların toplu halde bir tapınakta bulunması, tapınakta ibadet edilen bu tanrı veya tanrıçayı tipik bir şifa tanrı ya da tanrıçası olarak nitelemek için yeterlidir. Aynı şekilde kadın üreme organı ve rahim şeklindeki adaklar, tapınağın bir tür kadın doğurganlık merkezi olarak kabul edilmiş olabileceği yorumlarına yol açmıştır (Carroll, 2019, s. 1).

17 Sağlık tanrı ve tanrıçalarına adak olarak sunulmuş gerçek veya yapay saçlar, hastalıktan kurtulma seremonisinin bir parçası olarak kullanılmıştır (Draycott, 2017, s. 83). Bu bağlamda Pausanias, Hygieia'ya kadınlar tarafından sunulmuş adak saç buklelerinden söz etmektedir (Pausanias, Description of Greece, II.11.6). 
Iuno, Iuno Luciana epithetiyle doğumlardaki baş tanrıçadır ve yetişkinlik çağına gelene kadar hem erkek hem kız çocuklarının geçirdikleri her evreyi kontrol altında tutmuştur (Jayne, 1925, s. 449-450). Eski Yunan dünyasında sağlık tanrısı Asklepios'un kızı Hygeia ile bir tutulan Roma şifa tanrıçası ise Salus'tur. Hem devletin hem de bireyin refah, zenginlik ve sağlık tanrıçası Salus, şifacılık rolüyle sık sık sikke ve yazıtlarda tasvir edilmiştir ${ }^{18}$. Önceleri ülkenin güvenliğini sağlayan bir tanrıça olarak tapınılıp bu özelliğine ithafen II. Samnit Savaşı sırasında onun için tapınak inşa edilirken (Livius, IX. 43) MÖ 293'teki veba salgınında Asklepios'un Roma’ya çağrılmasından sonra Salus, Hygeia ile özdeşleşerek şifa tanrıçası rolüyle daha ön plana çıkmıştır (Beumer, 2016, s. 9; Jackson, 1999, s. 4).

\section{Sonuç}

Neredeyse Hellenistik Dönem’e kadar, Eski Yunan ve Roma dünyasında kadın şifacıları gösteren spesifik örneklerin olmayışı, Eski Yunan dünyasında erkeğin doğuştan getirdiği ve kadının yoksun olduğu sophrosyne ve retorik gibi birtakım erdemlere bağlanabileceği gibi Roma dünyasında da pater familias'ın hanedeki tüm görevleri, doğal olarak sağaltmayı da üstlenmesine bağlanabilir. Bunlar tek neden olmasa da temel ve en katı nedenler olmalıdır. Eski Yunan ve Romalılarda kadın, erkeğin doğuştan getirdiği erdemlerden yoksun olabilir fakat bir tanrıça ya da tanrısal dişi bir ruh, fani olan bir erkeğin niteliklerinin altında görülmemiş olmalıdır ki onlara şifacılıkta alan tanınmıştır. Diğer bir ifadeyle ataerkil bir sistemde erkekler şifacılık gibi kutsal bir alanda sıradan kadınları değil ancak tanrıçaları kendilerine denk görmüş ve antik kaynaklarda onlara yer vermeyi uygun görmüş olabilirler. Fakat yukarıda ele alınan tanrıçaların sağaltma nitelikleri incelendiğinde, bunların gerçek kadınlar olabileceği fikri güçlenmektedir. Şifacı tanrıçaların büyük çoğunluğu kadın ve çocukların hastalıklarıyla ilgileniyor görünmektedir. Oysa diğer niteliklerinin yanı sıra av tanrıçası olan Artemis neden av sırasında meydana gelen yaralanmalara şifa veren bir tanrıça değildir? Ya da savaş tanrıçası olan Athena, şifacılık panteonundaki görevinde neden savaş yaralarını tedavi etmemektedir? Bunun nedeni olarak, tanrıçaların şifacılık özellikleri yaratılırken, örnek alınan kadın modellerinin halk şifacılığında genellikle kadın hastalıkları, doğum ve çocuk hastalıklarıyla ilgilenmelerinden kaynaklı olduğu düşünülebilir. Buna rağmen, bazı kadınlar sağaltmadaki bu sınırlı alanın dışına çıkmış ve bitkisel alandaki uzmanlıklarını kanıtlamış olmalıdır ki model alındıklarında bitkisel bilgileriyle göz

18 Sikkeler için: Tanrıça Salus, Salus Publica (Halkın Sağlığı) imajıyla fiziksel sağlığın sembolü olarak, elinde bir patera tutarken (RIC II. HADRIAN, 604a) ya da bir yilanı beslerken (RSC I. ACILIA-AEMILIA, 8) Roma sikkelerinde tasvir edilmektedir. $\mathrm{Bu}$ sahne Livius'un bahsettiği bir hikayeye dayanmaktadır ki, hikayeye göre orduyu tedirgin eden bir salgının kaldırılması için Romalılar, Apollon, Asklepios ve tanrıça Salus'a başvurmuşlardır (Livius'un 40.37.2-3). Yazıtlar için bkz: (CIL VII. 2579). 1789'da Binchester'da, biri Asklepios diğeri Salus olmak üzere iki heykel figürü içeren bir adak tableti keşfedilmiştir. Yazıtın genel kabul görmüş çevirisi: "Roma vatandaşları Vettonların sağlı̆̆l ve güvenliği için Asklepios ve Salus'a hekim Marcus Aurelius Habrocomas tarafindan adandl." Yine British Museum'daki bir yazıtta, bu sunağın Asklepios ve kızı Salus'a adandığ 1 yazmaktadır (Barnes, 1914, s. 78-79). 
hastalıklarına ve körlüğe deva bulan Artemis, Athena ve cerrahi becerilere sahip Leto ortaya çıkmıştır. Yine bitkiler hakkındaki uzmanlıklarıyla Eski Yunan dünyasında tedavilerde bulunan ve günün koşullarında mucize sayıldığı için bu durumlara mantıklı bir cevap bulunamadığında büyücülükle itham edilen Kirke, Medeia ve Roma'nın ilk tanrıçalarından Angitia'nın şifacı kadınlar üzerinden yaratılan tanrıçalar olabileceğini göz ardı etmemek gerekmektedir. Roma'da ise temelde aynı olan tanrıçaların bazı epithetlerle şifacılıkta daha geniş bir yetki alanı ile tanınmış olmaları dikkat çekicidir. Örneğin Eski Yunan dünyasında Athena, Roma'da Minerva Medica epithetiyle hekimlerin özel hamisi, kulak hastalıklarına şifa veren, saçları onaran ve başka hastalıklar için şifa reçeteleri yazan bir tanrıça haline gelmiştir. Diana’nın, Eski Yunanistan'da Artemis kimliğinde üreme ve doğum anıyla daha ilgiliyken Roma'da birçok minyatür bacak, göğüs, karaciğer, oyuncak bebek, saç tutamı gibi hastalıklı organların kil, balmumu veya taştan birer minyatürün sunulduğu, diğer bir ifadeyle bu hastalıkları tedavi ettiğine inanılan bir tanrıça haline geldiği anlaşılmaktadır. Sadece kadın ve çocuk hastalıklarıyla sınırlandırılmayan şifacı kadınlar üzerinden yaratılan diğer bir tanrıça ise, hem erkeklerin hem de kadınların kalp, karaciğer, akciğer ve diğer iç organlarını koruyan Carna'dır. Dolayısıyla şifacı tanrıçaların temelde jinekolojik hastalıklar, doğum ve çocuk hastalıkları alanında tedavi işlemleri yaparken zamanla hem kadın hem erkek hastalıklarını kapsayan sağaltma alanında, tıbbi beceriler sergilerken tapınım görmeleri, şifacı tanrıça yaratımında model alınan kadın şifacıların tıbbi alandaki becerilerini geliştirip daha kapsamlı bir alanda tedavi uygulamış olmalarının tezahürü olmalıdır.

\section{Kisaltmalar}

CIL. Corpus Inscriptionum Latinarum.

IG. Inscriptiones Graecae.

IK Kyme. Die Inschriften von Kyme.

ILS. Inscriptiones Latinae Selectae.

RIC. The Roman Imperial Coinage.

RSC. Roman Silver Coins.

SEG. Supplementum Epigraphicum Graecum. 


\section{Kaynakça}

Achterberg, J. (2009). Kadın Şifacılar (B. Altınok, Çev.). İstanbul: Everest Yayınları.

Adkins L. \& Adkins R. A. (2004). Handbook to Life in Ancient Rome. New York: Facts On File.

Aristophanes, (1946). Aristophanes, Vol. III., The Lysistrata, The Thesmophoriazusae, The Ecclesiazusae, The Plutus (B. B. Rogers, Trans.). The Loeb Classical Library. Massachusetts: Harvard University Press.

Barnes, H. (1914). On Roman Medicine and Roman Medical Inscriptions Found in Britanian. Proc R Soc Med. 7, 71-87.

Beumer, M. (2016). Hygieia: Identity, Cult and Reception. Kleio-Historia, 3, 5-24.

Brouwer, H.H.J. (1989). Bona Dea: The Sources and a Description of the Cult. Leiden: E. J. Brill.

Capra, F. (1988). THE TURNING POINT: Science, Society and the Rising Culture. New York: Bantam Books.

Carroll, M. (2019). Mater Matuta, 'Fertility Cults', and the Integration of Women in Religious Life in Italy in the Fourth to First Centuries BC. PBSR, 87, 1-45. https://doi.org/10.1017/S0068246218000399

Çapar, Ö. (1978). Roma Tarihinde Magna Mater (Kybele) Tapınımı. DTCF Dergisi, 29(1-4), 167-210.

Çelgin, G.(2010). Eski Yunanca-Türkçe Sözlük. İstanbul: Kabalcı Yayınevi.

Daly, K. N. (2009). Greek and Roman Mythology A to Z. New York: Chelsae House Publishers.

Demand, N. (1994). Birth, Death, and Motherhood in Classical Greece. Baltimore - London: The Johns Hopkins University Press.

Demangel, R. (1922). Fouilles de Delos. Un Sanctuaire d'Artemis-Eileithyia a l'Est du Cynthe. BCH, 46, 58-93. Erişim adresi: http://www.persee.fr/doc/bch_0007-4217_1922_num_46_1_3029

Dickie, M. W. (2005). Magic and Magicians in the Greco-Roman World. London - New York: Routhledge.

Dikaios, P. (1961). A Guide to the Cyprus Museum. Nicosia: The Nicosia Printing Works Chr. Nicolaon \& Sons Ltd.

Diodorus Siculus (1989). Library of History. Vol. I (C.H. Oldfather, Trans.). Loeb Classical Library. Cambridge: Harvard University Press.

Draycott, J. (2017). Hair Today, Gone Tomorrow: The Use of Real, False and Artificial Hair as Votive Offering. Jane Draycott \& Emma-Jayne Graham (Eds.), Bodies of Evidence: Ancient Anatomical Votives Past Present and Future (pp. 77-94). London: Routledge.

Dubos, R. (1968). Man, Medicine and Environment. New York: Praeger.

Euripides (1912). Ion, Hippolytus, Medea, Alcestis. Vol. IV (Arthur S. W., Trans.). The Loeb Classical Library. London: William Heinemann, New York: The Macmillan Co.

Firatli N., \& Robert L. (1964). Les Steles Funeraires de Byzance Greco-Romaine. Paris: A. Maisonneuve.

Flemming, R. (2017). Wombs for the gods. Jane Draycott \& Emma-Jayne Graham (Eds.), Bodies of Evidence: Ancient Anatomical Votives Past Present and Future (pp. 112-130). London: Routledge.

Foley, H. P. (1994). The Homeric Hymn to Demeter. New Jersey: Princeton University Press.

Foucault, M. (1990). The use of Pleasure: Volume 2 of The History of Sexuality (Robert H. Trans.). New York: Vintage Books.

Graves, R. (2010). Yunan Mitleri: Tanrılar, Kahramanlar, Söylenceler (U. Akpur, Çev.). İstanbul: Say Yayınları. 
Herodotos (1920). Histories. Vol. I. Books 1-2 (A.D. Godley, Trans.). London: William Heinemann.

Hippocrates (1959). The Physician (Chapter I). Vol. II (W.H.S. Jones, Trans.). Loeb Classical Library. Cambridge: Harvard University Press.

Hippocrates (1995). Hippocrates, Fleshes. Vol. VIII (Paul Potter, Trans.). Loeb Classical Library. London: Harvard University Press.

Homeros (1924). The Iliad (A.T. Murray, Trans.). Cambridge: Harvard University Press.

Homeros (2005). Odysseia (A. Erhat ve A. Kadir, Çev.). İstanbul: Can Yayınları.

Hurd-Mead, K. C. (1938). A History of Women in Medicine. Haddam: The Haddam Press.

Irving, J. C. (2015). The Greek Epigraphic Evidence For Healer Women In The Greek World (Doctoral dissertatiton, Macquarie University, Sydney).

Jackson, R. (1999). Roma İmparatorluğunda Doktorlar ve Hastalıklar (Şenol Mumcu Çev.). İstanbul: Homer Kitabevi.

Jayne, W. A. (1925). The Healing Gods Of Ancient Civilizations. London: Yale University Press.

Just, R. (1989). Women in Athenian Law and Life. London and New York: Routledge.

Konstan, D. (2003). Shame in Ancient Greece. Soc. Res., 70 (4), 1031-1060. Erişim adresi: https://www.jstor. org/stable/40971960

Liddell, H. G., \& Scott, R. (1996). A Greek-English Lexicon. Oxford: Clarendon Press.

Littre, E. (1853). Oeuvres completes d'Hippocrate. Vol. VIII. Paris: Bailliere.

Lloyd, G.E.R. (1983). Science, Folklore and Ideology: Studies in the Life Sciences in Ancient Greece. Cambridge: Cambridge University Press.

Lomas, K. (2018). The Rise of Rome: From the Iron Age to the Punic Wars. Massachusetts: Harvard University Press.

Meier, C.A. (1985). Der Traum als Medizin: Antike Inkubation und moderne Psychotherapie. Zürich: Daimon Verlag.

Monaghan, P. (2014). Encyclopedia of Goddesses \& Heroines. Novato California: New World Library.

Neuburger, M. (1910). History of Medicine. Vol. I. London: Oxford University Press.

Paton, W. R. (1918). The Greek Anthology. Vol. III. Loeb Classical Library. London: William HeinemannNew York: G.P. Pugnam's Sons.

Pausanias, (1918). Description of Greece. Vol. I. Books 1-2 (W.H.S. Jones, Trans.). Loeb Classical Library. London: William Heinemann.

Pausanias, (1935). Description of Greece. Vol. IV. Books 8-10 (W.H.S. Jones, Trans.). Loeb Classical Library. Cambridge: Harvard University Press.

Petridou, G. (2017). Demeter as an Ophthalmologist? Eye Votives and The Cult of Demeter And Kore. Jane Draycott \& Emma-Jayne Graham (Eds.), Bodies of Evidence: Ancient Anatomical Votives Past Present and Future (pp. 95-111). London: Routledge.

Pichanick, A. (2016). Sôphrosunê, Socratic Therapy, and Platonic Drama in Plato's Charmides. Epoché, 21(1), 47-66.

Platon, (1881). The Theaetetus of Platon (Benjamin H. K., Trans.). Cambridge: At the University Press. 
Richardson, L. (1992). A New Topographical Dictionary of Ancient Rome. Baltimore and London: Hopkins University Press.

Richter, G. M. A. (1954). Catalogue of Greek Sculptures in Metropolitan Museum of Art. Massachusetts: Harvard University Press.

Rouse, W. H. D. (1902). Greek Votive Offerings. Cambridge: Cambridge University Press.

Smith, C. (2000). Worshipping Mater Matuta: Ritual and Context. Edward Bispham \& Christopher John Smith (Eds.), Religion in Archaic and Republican Rome and Italy: Evidence and Experience (pp. 136-156). Edinburgh, UK: Edinburgh University Press.

Strabon (1961). The Geography of Strabo. Vol. V. Books 10-12 (Horace L. J., Trans.). The Loeb Classical Library. London: Harvard University Press.

Tacitus Livius (2004). The Annals (A.J. Woodman, Trans.). Indianapolis/ Cambridge: Hackett Publishing Company, Inc.

Titus Livius (1926). Livy. Vol. IV. Books 8-10 (B.O. Foster, Trans.). The Loeb Classical Library. New York: William Heinemann London, G.P. Putnam's Sons.

Titus Livius (1935). Livy. Vol. IX. Books 31 - 34 (Evan T. Sage, Trans.). The Loeb Classical Library. Massachusetts: Harvard University Press.

Titus Livius (1936). Livy. Vol. XI. Books 38 - 39 (Evan T. Sage, Trans.). The Loeb Classical Library. London: Harvard University Press.

Titus Livius (1949). Livy. Vol. VIII. Books 28-30 (Frank G. M., Trans.). The Loeb Classical Library. Cambridge, Massahusetts: Harvard University Press.

Titus Livius (1979). Livy. Vol. XII. Books 40 - 42 (Evan T. S. \& Alfred C. S., Trans.). The Loeb Classical Library. Massachusetts: Harvard University Press.

Vergilius (1918). Aeneid VII-XII, The Minor Poems (H. Rushton Fairclough, Trans.). The Loeb Classical Library. London: William Heinemann, New York: G. P. Putnam's Sons.

Ward, P. S. (1988). Hygeia's Sisters: A History of Women in Pharmacy. Caduceus, 4, 1-58. 